\title{
Prevalence and progression of diabetes in mitochondrial disease
}

\author{
R. G. Whittaker • A. M. Schaefer • R. McFarland • \\ R. W. Taylor $\cdot$ M. Walker $\cdot$ D. M. Turnbull
}

Received: 29 May 2007 / Accepted: 18 June 2007 /Published online: 26 July 2007

(C) Springer-Verlag 2007

\begin{abstract}
Aims/Hypothesis The aims of this study were (1) to determine the prevalence and rate of progression in diabetes secondary to mitochondrial DNA (mtDNA) mutations; and (2) to determine whether percentage heteroplasmy predicts clinical outcome in patients carrying the $\mathrm{m} .3243 \mathrm{~A}>\mathrm{G}$ mutation. Methods We prospectively assessed 242 patients attending a specialist neuromuscular clinic using a validated mitochondrial disease rating scale. Retrospective clinical data on these patients from up to 25 years of follow-up were also included. Percentage heteroplasmy in blood, urine and muscle was determined for the m.3243A $>\mathrm{G}$ group and correlated against clinical features.

Results Patients carrying the m.3243A $>\mathrm{G}$ mutation formed the largest group of patients with diabetes (31/81 patients). The highest prevalence of diabetes was in the $\mathrm{m} .12258 \mathrm{C}>\mathrm{A}$ group ( $2 / 2$ patients), the lowest in the multiple mtDNA deletions group ( $3 / 43$ patients). The earliest age of onset was in the $\mathrm{m} .3243 \mathrm{~A}>\mathrm{G}$ group (37.9 years) with the highest age of presentation in the multiple deletion group (56.3 years). Of patients presenting with $\mathrm{m} .3243 \mathrm{~A}>\mathrm{G}, 12.9 \%$ required insulin; an additional $32.3 \%$ progressed to insulin requirement over a mean of 4.2 years after presentation. Percentage heteroplasmy in blood, urine or muscle did not predict progression of diabetes or risk of developing complications.
\end{abstract}

R. G. Whittaker $(\bowtie) \cdot$ A. M. Schaefer $\cdot$ R. McFarland

R. W. Taylor · D. M. Turnbull

Mitochondrial Research Group, School of Neurology,

Neurobiology and Psychiatry, Newcastle University,

Newcastle upon Tyne NE2 4HH, UK

e-mail: r.whittaker@ncl.ac.uk

\section{Walker}

Diabetes Research Group, School of Clinical Medical Sciences,

Newcastle University,

Newcastle upon Tyne, UK
Early age of presentation with diabetes did predict poor clinical outcome.

Conclusions/Interpretation Although patients carrying the m.3243A $>$ G mutation account for the majority of cases of diabetes secondary to mtDNA mutations, several other genotypes are also associated with the development of diabetes, some with high penetrance. All show a gradual progression to insulin requirement. Percentage heteroplasmy is a poor predictor of severity of diabetes in the $\mathrm{m} .3243 \mathrm{~A}>\mathrm{G}$ group.

Keywords Diabetes · Genotype · Heteroplasmy · Mitochondria $\cdot$ Mutations $\cdot$ Prevalence $\cdot$ Progression

\section{Abbreviation \\ mtDNA mitochondrial DNA}

\section{Introduction}

Diabetes mellitus is now established as one of the greatest healthcare problems of the industrialised world, affecting approximately $7 \%$ of the US population [1]. Genetic defects of beta cell function are increasingly being recognised and account for a small but significant proportion of patients who present with diabetes.

The association between mitochondrial disease and diabetes is now well established for the m.3243A $>$ G point mutation, in some populations accounting for up to $3 \%$ of all cases of diabetes [2,3]. Diabetes has also been reported in large-scale single deletions of mitochondrial DNA (mtDNA) $[4,5]$ and other point mutations in mitochondrial tRNA genes, such as m.14709T $>C$ [6, 7]. In addition, mutations of nuclear encoded mitochondrial genes affecting mtDNA replication and repair have been identified in 
mitochondrial diabetes [8]. Less clearly understood are the factors that determine the clinical phenotype for any particular genotype. For example, the m.3243A $>\mathrm{G}$ point mutation can give rise to different phenotypes including: asymptomatic; maternally inherited diabetes and deafness; chronic progressive external ophthalmoplegia; or a syndrome known as mitochondrial encephalomyopathy, lactic acidosis and stroke like-episodes. The high metabolic requirement of the tissues involved and the level of mutated to wild-type mtDNA (heteroplasmy) in the tissue are important [9]. However, these alone cannot explain the phenotypic variability and our understanding of the tendency of certain mutations to cause disease in particular tissues remains poor. Furthermore, in vivo assessment of heteroplasmy is extremely difficult in tissues such as pancreas. When postmortem investigations have been undertaken, the level of mutant heteroplasmy in surviving islet beta cells has been surprisingly low [10]. While this probably reflects selective loss of beta cells containing a high proportion of mutated mtDNA, this is by no means certain.

Understanding the mechanisms and natural history of diabetes in patients with mitochondrial disease is extremely important when it comes to providing patients and their families with prognostic advice. Here we present a large longitudinal clinical study of diabetes in patients with mitochondrial disease using data collected over the last 25 years. Comparison is made between different genotypes, in terms of onset, progression and complication rate of diabetes. In addition, mutant heteroplasmy levels in tissues such as blood, urine and muscle are reviewed to assess their predictive value for onset and progression of diabetes.

\section{Methods}

Patients Patients $(n=242)$ attending a specialist mitochondrial disease clinic with a positive diagnosis of mitochondrial disease based on muscle histochemistry or genetic testing were included in the study. All patients gave informed written consent and the study was approved by Newcastle and North Tyneside Local Research Ethics Committee. Patients attending this clinic are currently involved in a longitudinal study of mitochondrial disease and data have been collected prospectively using a validated rating scale for the last 2 years [11]. Retrospective data from the case notes were also collected. The period of retrospective analysis ranged from 3 to 25 years.

Definitions Diabetes was defined in accordance with WHO criteria [12]. Neuropathy was defined as glove and stocking sensory loss or areflexia; moreover, although supportive evidence from nerve conduction studies and electromyography was sought, this was not necessary for inclusion.
Hypertension was defined as a blood pressure of greater than $140 \mathrm{mmHg}$ systolic or $80 \mathrm{mmHg}$ diastolic. Renal impairment was defined as a plasma creatinine of greater than $120 \mu \mathrm{mol} / \mathrm{l}$. Retinopathy was assessed by a consultant ophthalmologist in all cases.

Genetic diagnosis All genetic diagnoses were made on DNA extracted from skeletal muscle, blood or urinary epithelial cells [13]. For patients thought to harbour a particular mtDNA point mutation, either on the basis of family history or from their clinical phenotype, a specific radioactive RFLP assay using the incorporation of a radiolabelled dNTP in the final PCR cycle was performed to allow quantification of mutation levels [14]. Other (novel) point mutations were identified through whole mitochondrial genome sequencing using overlapping forward and reverse primers [15]. For those patients with suspected large-scale single mtDNA deletions or multiple mtDNA deletions, long-range PCR and Southern blotting were employed [16]. Targeted gene sequencing, based on the patient's histochemistry and clinical phenotype, was used to identify nuclear DNA mutations.

Statistics Pearson's correlation co-efficient and Student's $t$ test were used. Data was analysed using SPSS version 11.0 (Microsoft, Thames Valley Park, Reading, UK). The level of significance was taken as 0.05 in all cases.

\section{Results}

Prevalence of diabetes Diabetes was diagnosed in patients with the following genotypes: $\mathrm{m} .3243 \mathrm{~A}>\mathrm{G}$ (31/81 patients), m. $8344 \mathrm{~A}>\mathrm{G}(3 / 29$ patients), m.14709T $>\mathrm{C}$ (7/13 patients), m. $12258 \mathrm{C}>\mathrm{A}$ ( $2 / 2$ patients) point mutations, single mtDNA deletion (6/55 patients), multiple mtDNA deletion as a result of mutation in polymerase (DNA directed), gamma (POLG1, also known as $P O L G)(2 / 3$ patients) and multiple mtDNA deletions with unknown nuclear genetic mutation (3/43 patients). Patients with 16 other mtDNA mutations were included in the study, none of whom had diabetes.

Age of diabetes onset and progression to insulin requirement Table 1 shows the mean age and mode of onset for each genotype. Age of diagnosis was similar in all groups with the earliest onset being found in the $\mathrm{m} .3243 \mathrm{~A}>\mathrm{G}$ group and the latest in the multiple deletion group. The percentage requiring insulin at presentation for the $\mathrm{m} .3243 \mathrm{~A}>\mathrm{G}$, m.8344A $>\mathrm{G}$ and $\mathrm{m} .14709 \mathrm{~T}>\mathrm{C}$ mutations were $12.9,66.6$ and 28.6 respectively. Age of onset in patients presenting with insulin requirement was significantly lower in the m.3243A $>$ G mutation (16.8 vs 37.9 years, $p<0.05)$ except 
Table 1 Onset and progression of diabetes in patients with mitochondrial disease

\begin{tabular}{|c|c|c|c|c|c|c|}
\hline Genotype & $\begin{array}{l}\text { Proportion } \\
\text { developing } \\
\text { diabetes, } n / n(\%)\end{array}$ & $\begin{array}{l}\text { Mean BMI, patients } \\
\text { with/without diabetes } \\
\left(\mathrm{kg} / \mathrm{m}^{2}\right)\end{array}$ & $\begin{array}{l}\text { Mean (SD) age at } \\
\text { presentation with } \\
\text { diabetes (years) }\end{array}$ & $\begin{array}{l}\text { Requiring } \\
\text { insulin at } \\
\text { presentation (\%) }\end{array}$ & $\begin{array}{l}\text { Progressing } \\
\text { to insulin } \\
\text { requirement (\%) }\end{array}$ & $\begin{array}{l}\text { Mean time } \\
\text { to insulin } \\
\text { (years) }\end{array}$ \\
\hline m. $3243 \mathrm{~A}>\mathrm{G}$ & $31 / 81(38.3)$ & $22.3 / 23.5$ & $37.9(15.1)$ & 12.9 & 45.2 & 4.2 \\
\hline $\mathrm{m} .8344 \mathrm{~A}>\mathrm{G}$ & $3 / 29(10.3)$ & & $40(22.0)$ & 66.6 & 66.6 & $\mathrm{n} / \mathrm{r}$ \\
\hline m.14709T $>C$ & 7/13 (53.8) & & $44.6(12.8)$ & 28.6 & 42.9 & 5.0 \\
\hline $\mathrm{m} .12258 \mathrm{~A}>\mathrm{C}$ & $2 / 2(100)$ & & $45(21.2)$ & 0 & 100 & 3.5 \\
\hline $\begin{array}{l}\text { Single large-scale } \\
\text { deletion }\end{array}$ & $6 / 55(10.9)$ & & $43(25.2)$ & 0 & 0 & $\mathrm{n} / \mathrm{r}$ \\
\hline$P O L G 1$ & $2 / 3(66.6)$ & & $49.5(0.7)$ & 0 & 0 & $\mathrm{n} / \mathrm{r}$ \\
\hline Multiple deletion & $3 / 43(7.0)$ & & $56.3(11.0)$ & 0 & 0 & $\mathrm{n} / \mathrm{r}$ \\
\hline
\end{tabular}

$n / r$ not relevant, POLG1 polymerase (DNA directed), gamma

for patients with $\mathrm{m} .8344 \mathrm{~A}>\mathrm{G}$ or $\mathrm{m} .14709 \mathrm{~T}>\mathrm{C}$ mutations. None of the patients requiring insulin had islet cell antibodies. No patients with other genotypes required insulin upon presentation, although both patients with the m.12258C $>$ A mutation progressed to insulin requirement after a mean of 3.5 years. There was no difference in the BMI of patients carrying the m.3243A $>\mathrm{G}$ mutation with and without diabetes (22.3 vs $\left.23.5 \mathrm{~kg} / \mathrm{m}^{2}, p>0.05\right)$.

Complications of diabetes We next examined the prevalence and progression of complications of diabetes (Table 2). We limited the analysis to the $\mathrm{m} .3243 \mathrm{~A}>\mathrm{G}$ mutation, as this was by far the largest group. Of 31 patients with diabetes, $18(58 \%)$ had evidence of peripheral neuropathy compared with 4 out of 50 without diabetes $(8 \%)$. Patients presented with this at a mean of 6.75 years after diabetes diagnosis. No differences in the age of onset of diabetes (34.1 vs 37.9 years, $p>0.05$ ) were detected between patients with and without neuropathy. Four patients $(12.9 \%)$ with diabetes and none without developed renal impairment at a mean of 12.75 years after the onset of diabetes. These patients presented with diabetes at a significantly younger age (25.8 vs 37.9 years, $p<0.05)$. Hypertension was present in eight patients $(25.8 \%)$ with and three patients without diabetes, being diagnosed at a mean of 13.2 years after onset of diabetes. Two of these patients also developed left ventricular hypertrophy. As with renal impairment, these patients had also presented with diabetes at a significantly younger age (29.2 vs 37.9 years, $p<0.05)$. Information on retinal screening was available for 23 of 31 patients. Three patients (13\%) had changes associated with diabetic retinopathy, occurring at a mean of 5.6 years after diagnosis.

Correlation between mutation load and diabetes Analysis was limited to the group of patients with the m.3243A $>\mathrm{G}$ mutation, as this was by far the largest group. We were able to determine the mutation load in muscle or blood in 29 of 31 patients with diabetes and 48 of 50 patients without diabetes.

There was no significant difference in the mean heteroplasmy level between patients with and without diabetes in either muscle (59.8 vs $53.3 \%, p>0.05)$ or blood (16.2 vs $20.3 \%, p>0.05)$. In the group of patients with diabetes, Pearson correlation analysis showed age of onset to be negatively correlated with percentage heteroplasmy in blood $(R=-0.484, p<0.05)$ but not in muscle $(R=-0.068$, $p>0.05)$. There was no correlation between likelihood of requiring insulin at presentation and percentage heteroplasmy

Table 2 Complications of diabetes in patients with $\mathrm{m} .3243 \mathrm{~A}>\mathrm{G}$

\begin{tabular}{|c|c|c|c|c|c|}
\hline Patient subgroups & $\begin{array}{l}\text { Mean muscle } \\
\text { heteroplasmy level (\%) }\end{array}$ & $\begin{array}{l}\text { Age at diabetes } \\
\text { diagnosis (years) }\end{array}$ & $\begin{array}{l}\text { Prevalence in patients } \\
\text { with/without diabetes (\%) }\end{array}$ & $\begin{array}{l}\text { Time from diagnosis } \\
\text { of diabetes (years) }\end{array}$ & Mean $\mathrm{HbA}_{1 \mathrm{c}}(\%)$ \\
\hline $\begin{array}{l}\text { All patients with } \\
\text { m.3243A }>\text { G }\end{array}$ & 53.3 & & & & \\
\hline $\begin{array}{l}\text { All patients with } \\
\text { m.3243A }>\text { G and } \\
\text { diabetes }\end{array}$ & 59.8 & 37.9 & & & 6.47 \\
\hline +Neuropathy & 54.1 & 34.1 & $58 / 8$ & 6.75 & 7.06 \\
\hline +Renal impairment & 49.0 & 25.8 & $12.9 / 0$ & 12.75 & 7.80 \\
\hline +Hypertension & 58.1 & 29.2 & $25.8 / 6$ & 13.2 & 7.25 \\
\hline +Retinopathy & 49.5 & 24.0 & $13.0 / 0$ & 5.6 & 8.20 \\
\hline
\end{tabular}


in either muscle or blood, nor was there a correlation between time taken to progress to insulin requirement and percentage heteroplasmy.

We also wanted to see whether mutation load could predict the occurrence of diabetes-related complications. No correlation was found between muscle, urine or blood heteroplasmy levels and the risk of developing any of the complications of diabetes examined (data not shown). Mean $\mathrm{HbA}_{1 \mathrm{c}}$ level did predict the occurrence of both renal impairment and diabetic retinopathy $(p<0.05)$, although there was no significant difference in mean $\mathrm{HbA}_{1 \mathrm{c}}$ level in patients with and without neuropathy or hypertension.

\section{Discussion}

The most common association between mitochondrial DNA mutations and diabetes is seen in the m.3243A $>\mathrm{G}$ mutation, the group forming the majority of our patients with diabetes. However, as in previous studies, we observed the development of diabetes associated with several other genotypes. Indeed, although they represented only a small proportion of the total, patients carrying the $\mathrm{m} .12258 \mathrm{C}>\mathrm{A}$ and m.14709T $>C$ point mutation showed the highest likelihood of developing diabetes.

The age of onset in all genotypes was broadly similar with onset occurring typically in middle age. The mean age in the m.3243A $>$ G group (37.9 years) agreed well with results from a large Dutch cohort of patients [17]. In the Dutch cohort almost all patients had developed diabetes by the age of 70 years. It is not possible to say whether our cohort will also show the same degree of penetrance as we have not yet been able to follow all our patients into old age.

Significant correlation was found between the age of onset of diabetes and the risk of subsequently developing renal impairment or hypertension. Similarly, patients developing either renal impairment or diabetic retinopathy had a significantly higher mean $\mathrm{HbA}_{1 \mathrm{c}}$ level than those who did not. Our study emphasises the need for good glycaemic control, irrespective of the underlying aetiology of diabetes. The prevalence, for example, of retinopathy, neuropathy and renal failure was higher in our cohort than that found in either the United Kingdom Prospective Diabetes Study in type 2 diabetes or the DCCT in type 1 diabetes [18, 19], suggesting a more aggressive form of disease in our cohort.

We next asked the question whether m.3243A $>$ G heteroplasmy levels either predicted the risk of developing diabetes or, in patients already diagnosed with diabetes, predicted the risk of developing complications. A negative correlation between age of diabetes onset and blood heteroplasmy level was observed. This is likely to reflect the known decline in blood mutation level over time [20], those patients present- ing later having had longer for the level of mutation in the blood to fall. As such, this is not a clinically useful association and does not imply a causal link between the two parameters. For further analysis, we only used the level of m.3243A $>\mathrm{G}$ mutation in muscle, as this most closely correlates to the progression of other features of mitochondrial disease. No correlation was seen between age of onset or rate of diabetes progression and mutation load. Similarly, no correlation was found between heteroplasmy level and the risk of developing complications of diabetes. This is somewhat disappointing, as it indicates that even if mutation load in muscle is known at disease presentation, it is of no use with regard to provision of prognostic advice to patients. Perhaps this is not surprising, as it is well known that heteroplasmy levels vary between tissues [21]; in addition, the level of mutation in skeletal muscle may not accurately reflect that in the pancreas.

In conclusion, we found that in our cohort of patients a wide range of mutations of mitochondrial DNA was associated with diabetes, with patients carrying the $\mathrm{m} .3243 \mathrm{~A}>\mathrm{G}$ mutation representing by far the largest group. All genotypes showed a gradual progression to insulin requirement consistent with a progressive decline in beta cell function. In the m.3243A $>\mathrm{G}$ group, age of onset, speed of progression to insulin requirement and development of complications correlated poorly with muscle heteroplasmy levels. We recommend routine screening for complications of diabetes in all patients with mitochondrial disease-related diabetes, irrespective of their mutation load. We also recommend that particular attention be focussed on mitochondrial disease patients presenting with diabetes under the age of thirty.

Duality of interest The authors declare that there is no duality of interest associated with this manuscript.

\section{References}

1. National Institutes of Health (2005) National diabetes statistics fact sheet: general information and national estimates on diabetes in the United States, 2005. Department of Health and Human Services, National Institutes of Health, Bethesda, MD

2. Ohkubo K, Yamano A, Nagashima M et al (2001) Mitochondrial gene mutations in the tRNA(Leu(UUR)) region and diabetes: prevalence and clinical phenotypes in Japan. Clin Chem 47:1641-1648

3. Walker M, Taylor RW, Turnbull DM (2005) Mitochondrial diabetes. Diabetes Med 22(Suppl 4):18-20

4. Ballinger SW, Shoffner JM, Hedaya EV et al (1992) Maternally transmitted diabetes and deafness associated with a $10.4 \mathrm{~kb}$ mitochondrial DNA deletion. Nat Genet 1:11-15

5. Dunbar DR, Moonie PA, Swingler RJ, Davidson D, Roberts R, Holt IJ (1993) Maternally transmitted partial direct tandem duplication of mitochondrial DNA associated with diabetes mellitus. Hum Mol Genet 2:1619-1624

6. Hanna MG, Nelson I, Sweeney MG et al (1995) Congenital encephalomyopathy and adult-onset myopathy and diabetes mellitus: different phenotypic associations of a new heteroplasmic 
mtDNA tRNA glutamic acid mutation. Am J Hum Genet 56: 1026-1033

7. McFarland R, Schaefer AM, Gardner JL et al (2004) Familial myopathy: new insights into the T14709C mitochondrial tRNA mutation. Ann Neurol 55:478-484

8. Kiechl S, Horvath R, Luoma P et al (2004) Two families with autosomal dominant progressive external ophthalmoplegia. J Neurol Neurosurg Psychiatry 75:1125-1128

9. Chinnery PF, Howell N, Lightowlers RN, Turnbull DM (1997) Molecular pathology of MELAS and MERRF. The relationship between mutation load and clinical phenotypes. Brain 120:17131721

10. Lynn S, Borthwick GM, Charnley RM, Walker M, Turnbull DM (2003) Heteroplasmic ratio of the A3243G mitochondrial DNA mutation in single pancreatic beta cells. Diabetologia 46:296-299

11. Schaefer AM, Phoenix C, Elson JL, McFarland R, Chinnery PF, Turnbull DM (2006) Mitochondrial disease in adults: a scale to monitor progression and treatment. Neurology 66:1932-1934

12. Alberti KG (1999) Definition, diagnosis and classification of diabetes mellitus and its complications: report of a WHO consultation. Part 1, Diagnosis and classification of diabetes mellitus. World Health Organization, Department of Noncommunicable Disease Surveillance, Geneva, Switzerland

13. Taylor RW, Schaefer AM, Barron MJ, McFarland R, Turnbull DM (2004) The diagnosis of mitochondrial muscle disease. Neuromuscul Disord 14:237-245
14. McDonnell MT, Schaefer AM, Blakely EL et al (2004) Noninvasive diagnosis of the 3243A $>\mathrm{G}$ mitochondrial DNA mutation using urinary epithelial cells. Eur J Hum Genet 12:778-781

15. Taylor RW, Taylor GA, Durham SE, Turnbull DM (2001) The determination of complete human mitochondrial DNA sequences in single cells: implications for the study of somatic mitochondrial DNA point mutations. Nucleic Acids Res 29:E74

16. Blakely EL, He L, Taylor RW et al (2004) Mitochondrial DNA deletion in "identical" twin brothers. J Med Genet 41:e19

17. Maassen JA, 'T Hart LM, Van Essen E et al (2004) Mitochondrial diabetes: molecular mechanisms and clinical presentation. Diabetes 53(Suppl 1):S103-S109

18. Adler AI, Stevens RJ, Manley SE, Bilous RW, Cull CA, Holman RR (2003) Development and progression of nephropathy in type 2 diabetes: the United Kingdom Prospective Diabetes Study (UKPDS 64). Kidney Int 63:225-232

19. The Diabetes Control and Complications Trial Research Group (1993) The effect of intensive treatment of diabetes on the development and progression of long-term complications in insulindependent diabetes mellitus. N Engl J Med 329:977-986

20. Rahman S, Poulton J, Marchington D, Suomalainen A (2001) Decrease of $3243 \mathrm{~A} \rightarrow \mathrm{G}$ mtDNA mutation from blood in MELAS syndrome: a longitudinal study. Am J Hum Genet 68:238-240

21. Chinnery PF, Zwijnenburg PJ, Walker M et al (1999) Nonrandom tissue distribution of mutant mtDNA. Am J Med Genet 85: 498-501 